\title{
A Comparison of Start-Up Demonstration Test Procedures Based on a Combinatorial Approach
}

\author{
Amos E. Gera \\ SCE Shamoon College of Engineering \\ Zabotinsky 84, Ashdod, Israel \\ E-mail: amosgera@gmail.com
}

(Received December 21, 2017; Accepted January 10, 2018)

\begin{abstract}
A comparative study is presented of various start-up demonstration procedures based on a combinatorial approach. The expected number of required tests and the probability of accepting the tested unit are derived using a set of auxiliary functions. A constrained optimization problem is solved for minimizing the number of required tests subject to some confidence level requirements. The variables for this optimization include the total number of successes, failures, and the maximal lengths of runs of successes and failures. Various extensions to scan statistic-based and weighted tests are included and also to the testing of several units in parallel. The alternative Markov Chain embedding approach might involve in some cases the inversion of very large matrices. This disadvantage does not exist here.
\end{abstract}

Keywords- Start-up demonstration tests, Acceptance testing, Expected number of tests, Probability of acceptance.

\author{
Acronyms \\ TSTF Total successes total failures. \\ CSTF Consecutive successes total failures. \\ TSCSTF Total successes consecutive successes total failures. \\ TSCSTFCF Total successes consecutive successes total failures consecutive failures. \\ i.i.d. Identical Independent Distributed.
}

\section{Notation}

$N \quad$ The total number of start-ups (trials) until termination of the experiment.

$\mathrm{E}\{N\} \quad$ Expected number of $N$.

SD The standard deviation for $N$.

$P_{a} \quad$ The probability of acceptance of the unit.

$\mathrm{u}[$.$] \quad The unit step function.$

$\delta[$.$] \quad The delta function.$

$X_{i} \quad$ Outcome of $i$-th start-up test ( $=1$ for success, $=0$ for failure).

\section{Introduction}

Start-up demonstration tests are set up for proving the reliability of different kinds of equipment like lawn mowers, batteries, power generators, and so on. A whole bunch of procedures has been developed during the last decades for this purpose. In general, the results of these tests yield to the decision whether to accept or to reject the unit that is tested. The underlying theory is based on the theory of runs. Runs are sets of consecutive successes or failures and they are related to the commonly known consecutive $\mathrm{k}_{\mathrm{c}}$-out-of-n systems. A survey of the theory may be found, for instance, in a book (Kuo and Zuo, 2003) and in a paper (Eryilmaz, 2010). 
International Journal of Mathematical, Engineering and Management Sciences

Vol. 3, No. 3, 195-219, 2018

https://dx.doi.org/10.33889/IJMEMS.2018.3.3-015

There exist several ways of handling start-up demonstration tests. These include using generating functions, the Markov Chain Embedding technique (MCE) and the present combinatorial approach. An extensive survey of the various start-up procedures has been presented in a paper by Balakrishnan et al. (2014). At first, the CS (Consecutive Successes) procedure was introduced by Hahn and Gage (1983) and by Viveros and Balakrishnan (1993). Accordingly, the tested unit is accepted if there exists a consecutive set of $k_{c s}$ successes. Thereafter, Gera (2004) presented the TSCS (Total Successes Consecutive Successes) model. Further, on, adding the number of failures into the procedure, the CSTF procedure evolved. The equipment is accepted if there exists a consecutive of $k_{c s}$ successes and it is rejected if $\mathrm{k}_{\mathrm{f}}$ failures appeared before (Balakrishnan and Chan, 2000; Eryilmaz and Chakraborti, 2008; Martin, 2004, 2008; Smith and Griffith, 2005, 2008). A generalization of these models to the TSCSTF (Total Successes Consecutive Successes Total Failures) and TSCSTFCF (Total Successes Consecutive Failures Total Failures Consecutive Failures) procedures have been carried out by Gera (2010, 2011). Accordingly, accepting the tested unit if either $k_{s}$ successes or a run of length $k_{c s}$ successes are encountered before the counting of $k_{f}$ failures and the appearance of a run of $k_{c f}$ consecutive failures. Otherwise, the unit is rejected. At first, these models included simple I. I. D. binary tests (success or failure). Thereafter, previous sum dependent tests have been handled where the probability of the success of each test depends on the total number of previous successes (Velaisamy et al., 1996, 2007; Yalcin and Eryilmaz, 2012; Gera, 2013). Extensions have also been carried out to multi-state tests (Gera, 2013; Rakitzis and Antzoulakos, 2015; Smith and Griffith, 2011; Zhao et al., 2015).

The attribution of weights to consecutive components has been known before (Eryilmaz et al., 2010, 2009, 2014; Kamalija and Amrutkar, 2014). Recently, it has been suggested to use a procedure for which a weight is related to each test (Gera, 2015). Accordingly, the sum of the weights of consecutive successes replaces the actual number of consecutive successes within a run. The same goes with runs of failures.

The scan statistic-based CSDF procedure and its generalized version TSCSTFDF procedure (Total Successes Consecutive Successes Total Failures Distant Failures) have been handled by (Antzoulakos et al., 2009; Gera, 2013; Zhao et al., 2015). Accordingly, introducing an additional parameter $r$, the tested equipment is accepted if there exists a run of successes of a fixed length $\left(k_{c s}\right)$ or a total number of successes $\left(k_{s}\right)$ before either a total number of $k_{f}$ failures or the occurrence of two failures that have less than $r-1$ successes between them (so that they are too close to each other).

The above single-dimensional concept may be generalized to the two-dimensional case (Gera, 2014; Zuo, 1993). This involves testing $M$ units in parallel. Work in this direction has been presented by Zhao et al. (2010) for the case of $M=2$ units. The extended procedure works as follows. The equipment is accepted if either there is a total of $k_{s}$ successes or if all $M$ units have successes along the same consecutive $k_{c s}$ tests (so that we have a rectangular grid of $M \mathrm{x} k_{\mathrm{cs}}$ successes). It is rejected if before fulfilling these criteria for success, either there is a total of $k_{f}$ failures or if all units fail at the occurrence of the same consecutive $k_{c f}$ tests (thus creating a rectangular grid consisting of $M \times k_{\mathrm{cf}}$ failures).

For the purpose of designing a set of demonstration tests, two quantities are of interest. The basic one is the number of tests $(N)$ that will be involved and it is represented by their expected number $E\{N\}$. In addition, we are interested in the probability of success and of accepting the tested unit 
International Journal of Mathematical, Engineering and Management Sciences

Vol. 3, No. 3, 195-219, 2018

https://dx.doi.org/10.33889/IJMEMS.2018.3.3-015

$\left(P_{a}\right)$. The methods of their calculation include generating functions and the Finite Markov Chain Embedding approach.

The present paper indicates that in some cases it is preferable to use the combinatorial approach to evaluate the quantities of interest. It consists of defining auxiliary probability functions through which the parameters of interest are calculated. There are cases for which the Markov Chain Embedding approach involves the inversion of very large scale matrices. Sometimes it seems to be impractical and even impossible to carry out this task. This is evident when we handle the option of running several units in parallel (the two-dimensional case). Our way requires in some instances less CPU time and, as it will be seen, there is nearly no need for storage space . Further on, an optimization problem of minimizing the expected number of required tests subject to come confidence level constraints is solved. The present technique also proved to be useful for solving nearby problems like (Gera, 2011).

\section{Basic Quantities}

For I. I. D., binary tests, Table 1 presents some closed-form expressions for the above mentioned two quantities in relation to various basic procedures. Let $N$ be the random variable representing the total number of required tests, $E\{N\}$ the expected number and $P_{a}$ the probability of accepting the tested unit.

Table 1. $E\{N\}$ and $P_{a}$ for various procedures

\begin{tabular}{|c|c|c|c|}
\hline Procedure & $\mathrm{E}\{N\}$ & $P_{a}$ & Reference no. \\
\hline TS & $\frac{k_{s}}{p}$ & 1 & \\
\hline $\mathrm{CS}$ & $\frac{1-p^{k_{c s}}}{q p^{k_{c s}}}$ & 1 & Viveros et al. (1993) \\
\hline TSTF & & $p^{k_{s}} \cdot \sum_{n=0}^{k_{f}-1}\left(\begin{array}{c}n+k_{s}-1 \\
k_{s}-1\end{array}\right) \cdot q^{n}$ & $\begin{array}{l}\text { Balakrishnan et al. (2014), } \\
\text { Smith et al. (2008) }\end{array}$ \\
\hline $\mathrm{CSCF}$ & $\frac{\left(1-p^{k_{c s}}\right)\left(1-q^{k_{c f}}\right)}{p q\left[1-\left(1-p^{k_{c s}-1}\right)\left(1-q^{k_{c f}-1}\right.\right.}$ & $\frac{p^{k_{c s}-1}\left(1-q^{k_{c f}}\right)}{1-\left(1-p^{k_{c s}-1}\right)\left(1-q^{k_{c f}-1}\right)}$ & $\begin{array}{l}\text { Balakrishnan et al. (2014), } \\
\text { Smith et al. (2008) }\end{array}$ \\
\hline CSTF & $\frac{\left(1-p^{k_{c s}}\left[1-\left(1-p^{k_{c s}}\right)^{k_{f}}\right]\right.}{q p^{k_{c s}}}$ & $1-\left(1-p^{k_{c s}}\right)^{k_{f}}$ & Balakrishnan et al. (2000) \\
\hline CSDF & $\frac{\left(1-p^{k_{c s}}\right)\left(2-p^{r-1}\right)}{q\left(1+p^{k_{c s}}-p^{r-1}\right)}$ & $\frac{p^{k_{c s}}\left(2-p^{r-1}\right)}{1-p^{r-1}+p^{k_{c s}}}$ & Antzoulakos et al. (2009) \\
\hline
\end{tabular}


International Journal of Mathematical, Engineering and Management Sciences

Vol. 3, No. 3, 195-219, 2018

https://dx.doi.org/10.33889/IJMEMS.2018.3.3-015

To evaluate $E\{N\}$ for more complicated cases, we first determine the values of the function $h(n)=$ $P\{N>n\}$ with aid of auxiliary functions that will be presented further on.

Then,

$P\{N=n\}=P\{N>n-1\}-P\{N>n\}$

and thus we will obtain the value of $\mathrm{E}\{N\}$

Regarding the probability of acceptance $P_{a}$, it may result owing to two occurrences: either the required total number of successes $\left(k_{s}\right)$ is encountered or a specified run of $k_{c s}$ consecutive successes is achieved before meeting either a certain total number of failures $\left(k_{f}\right)$ or a specified run of $k_{c f}$ failures. $P_{a, 1}$ will denote the probability for the first case and $P_{a, 2}$ for the second case.

Then,

$P_{a}=P_{a, 1}+P_{a, 2}$

This scheme was applied to the various procedures in the following section.

\section{Auxiliary Functions}

The above probability functions of interest (1), (2), were calculated with aid of some auxiliary functions. Table 2 presents these various functions and the interrelations between them are given in Table 3. Some additional notation is needed for each procedure, as follows:

For binary i.i.d. tests and previous sum dependent tests (TSCSTFCF):

$p_{\mathrm{t}}, q_{\mathrm{t}} \quad$ probability of success, failure of $t^{\prime}$ th trial (=p for I. I. D. tests).

$k_{s} \quad$ the number of successes required for acceptance.

$k_{c s} \quad$ the number of consecutive successes required for acceptance.

$k_{f} \quad$ the number of failures yielding rejection.

$k_{c f} \quad$ the number of consecutive failures yielding rejection.

$L_{n, s} \quad$ the length of the longest run of successes throughout $n$ tests.

$L_{n, f} \quad$ the length of the longest run of failures throughout $n$ tests.

$T_{n, s} \quad$ the number of successful start-ups throughout $n$ tests.

$T_{n, f} \quad$ the number of failed start-ups throughout $n$ tests.

Adding the possibility of degradation as a third state result of each test, we introduce an example of a multi-state set of tests with the additional notation:

$p_{0} \quad$ probability of failure of each trial.

$p_{1} \quad$ probability of full success of each trial.

$p_{2} \quad$ probability of degradation of each trial.

$k_{s d} \quad$ the number of successes and/or degradations required for acceptance.

$k_{c s d} \quad$ the number of consecutive full successes and/or degradations required for acceptance.

$L_{n s} \quad$ the length of the longest run of full successes throughout $n$ tests.

$L_{n s d}$ the length of the longest run of full successes and/or degradations throughout $n$ tests. 
International Journal of Mathematical, Engineering and Management Sciences

Vol. 3, No. 3, 195-219, 2018

https://dx.doi.org/10.33889/IJMEMS.2018.3.3-015

$T_{n s} \quad$ the number of fully successful start-ups throughout $n$ tests.

$T_{n d} \quad$ the number of degraded start-ups throughout $n$ tests.

$T_{n s d} \quad$ the number of fully successful and/or degraded start-ups throughout $n$ tests.

According to the procedure that involves distant failures (TSCSTFDF), the tested equipment is accepted if there exists a run of successes of a fixed length $\left(k_{c s}\right)$ or a total number of successes $\left(k_{s}\right)$ before either a total number of $k_{f}$ failures or the occurrence of two failures that have less than $r-1$ successes between them (so that they are too close to each other). It involves the following notations:

$D_{n f} \quad$ the minimal spacing between adjacent failures throughout $n$ tests

$r-2$ the maximal number of successes between failures causing rejection

We can relate to each test a certain relative weight. Then we observe the sum of the weights of consecutive successes and/or failures $\operatorname{TSCSTFCF}_{\mathrm{w}}(\mathrm{Gera}, 2015)$. Accordingly, the tested unit is accepted if either the total weight of successes is at least $k_{w s}$ or a run of consecutive successes has a weight of at least $k_{c w s}$ before the meeting a certain number of failures with total weight $k_{w f}$ and before meeting a run of consecutive failures with total weight of at least $k_{c w f}$ (and vice versa). The following notations are then needed:

$w(n) \quad$ the weight of the n'th test.

$p_{\mathrm{t}}, q_{\mathrm{t}} \quad$ probability of success, failure of $t^{\prime}$ th trial ( $=p$ for I. I. D. tests).

$k_{w s} \quad$ total weight of successes required for acceptance.

$k_{w f} \quad$ total weight of failures yielding rejection.

$k_{c w s} \quad$ weight of a run of consecutive successes required for acceptance.

$k_{c w f} \quad$ weight of a run of consecutive failures yielding failure.

$L_{n w s} \quad$ weight of longest run of consecutive successes till $n$ (inclusive).

$L_{n w f} \quad$ weight of longest run of consecutive failures till $n$ (inclusive).

$T_{n w s} \quad$ total weight of successes till $n$ (inclusive).

$T_{n w f} \quad$ total weight of failures till $n$ (inclusive).

The following generalization to the two-dimensional (planar) case has been presented (Gera, 2014). The tested unit is accepted if either there is a total of $k_{s}$ successes or if $M$ units have successes along the same consecutive $k_{c s}$ tests (so that we have a rectangular grid of $M \mathrm{x} k_{\mathrm{cs}}$ successes). It is rejected if before fulfilling these criteria for success, either there is a total of $k_{f}$ failures or if the $M$ units fail at the same consecutive $k_{\mathrm{cf}}$ tests (rectangular grid consisting of $M \mathrm{x} k_{\mathrm{cf}}$ failures).

The following notations are added:

$M \quad$ the number of units included in the test procedure.

$T_{n, s} \quad$ the total number of successful start-ups counting all $M$ units throughout $n$ tests.

$T_{n, f} \quad$ the total number of failed start-ups counting all $M$ units throughout $n$ tests.

$R_{M, n, s}$ the maximal area of a rectangular grid of $\left(M, L_{n, s}\right)$ successes throughout $n$ tests for $M$ units.

$R_{M, n, f}$ the maximal area of a rectangular grid of $\left(M, L_{n, f}\right)$ failures throughout $n$ tests for $M$ units.

$k_{c s} \quad$ the common number of consecutive successes $\left(L_{n, s}\right)$ within $R_{M, n, s}$ yielding acceptance of the equipment. 
International Journal of Mathematical, Engineering and Management Sciences

Vol. 3, No. 3, 195-219, 2018

https://dx.doi.org/10.33889/IJMEMS.2018.3.3-015

$k_{c f} \quad$ the common number of consecutive failures $\left(L_{n, f}\right)$ within $R_{M, n, f}$ yielding failure using the above notations, the following auxiliary functions have been introduced.

Table 2. The definition of auxiliary functions for the various procedures

\begin{tabular}{|c|c|c|}
\hline Procedure & Auxiliary functions & References \\
\hline Binary & $f_{r}\left(i, k_{c s}, k_{c f}, n\right)=P\left\{T_{n, s}=i, L_{n, s}<k_{c, s}, L_{n, f}<k_{c, f}, X_{n}=r\right\}, r=0,1$ & $\begin{array}{l}\text { Gera }(2010, \\
2011)\end{array}$ \\
\hline Multi-state & $\begin{array}{l}f_{r}\left(i, j, k_{c s}, k_{c s d}, k_{c f}, n\right)= \\
P\left\{T_{n s}=i, T_{n d}=j, L_{n s}<k_{c s}, L_{n s d}<k_{c s d}, L_{n f}<k_{c f}, X_{n}=r\right\}^{r=0,1,2}\end{array}$ & Gera (2013) \\
\hline $\begin{array}{l}\text { Distant } \\
\text { failures }\end{array}$ & $f_{t}(i, n)=P\left\{T_{n s}=i, L_{n s}<k_{c s}, D_{n f}>r-2, X_{n}=t\right\}, t=0,1$ & Gera (2013) \\
\hline Weighted & $f_{t}(i, j, n)=P\left\{T_{n w s}=i, T_{n w f}=j, L_{n w s}<k_{c w s}, L_{n w f}<k_{c w f}, X_{n}=t\right\}, t=0,1$ & Gera (2015) \\
\hline Planar & $\begin{array}{l}f(i, j, n)= \\
P\left\{T_{n, s}=i, R_{M, n, s}<M k_{c s}, R_{M, n, f}<M k_{c f}, \underline{X}_{n}=\underline{V}(:, j)\right\} \\
\text { where } u=2^{M-m}, \\
\text { and for any } M \geq m \geq 1,2^{M} \geq j \geq 1, \text { and any specific } \\
2^{M} \geq r \geq 0, \\
V(m, j)=\left\{\begin{array}{cc}0 & (2 r+1) u \geq j>2 r u \\
1 & (2 r+2) u \geq j>(2 r+1) u\end{array}\right\}\end{array}$ & Gera (2014) \\
\hline
\end{tabular}

The difference equations that are valid for these auxiliary functions have been presented in various references as follows.

Table 3.The interconnecting relations between the auxiliary functions

\begin{tabular}{|c|c|}
\hline Procedure & Interconnecting relations \\
\hline Binary i.i.d. & 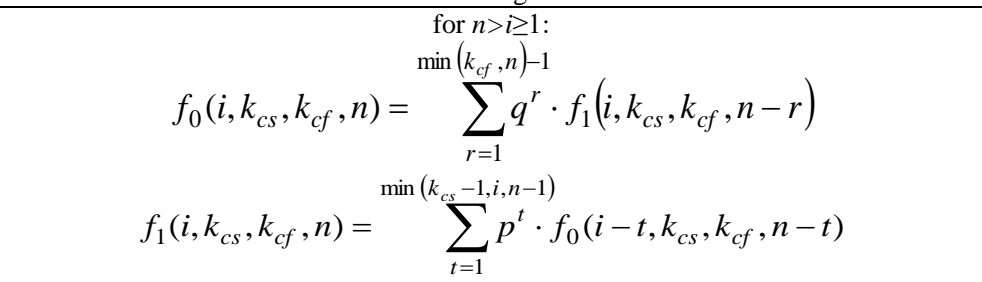 \\
\hline $\begin{array}{c}\text { Binary } \\
\text { dependent }\end{array}$ & $\begin{array}{c}\text { for } n>i \geq 1: \\
f_{0}\left(i, k_{c s}, k_{c f}, n\right)=\sum_{s=1}^{\min \left(k_{c f}, n\right)-1} \prod_{j=1}^{s}\left[1-c_{i, n-j+1}\right] \cdot f_{1}\left(i, k_{c s}, k_{c f}, n-s\right) \\
f_{1}\left(i, k_{c s}, k_{c f}, n\right)=\sum_{t=1}^{\min \left(k_{c s}-1, i, n-1\right)}\left(\prod_{j=1}^{t} c_{i-j, n-j+1}\right) \cdot f_{0}\left(i-t, k_{c s}, k_{c f}, n-t\right) \\
P\left\{X_{n}=1 \mid T_{n-1, s}=i\right\}=a_{n}+i \cdot b_{n}=c_{i, n} \\
a_{n}=\left(1-\theta_{n}\right) \cdot p_{1}, b_{n}=\frac{\theta_{n}}{n-1} \\
\theta_{n} \leq 1\end{array}$ \\
\hline
\end{tabular}


International Journal of Mathematical, Engineering and Management Sciences

Vol. 3, No. 3, 195-219, 2018

https://dx.doi.org/10.33889/IJMEMS.2018.3.3-015

\begin{tabular}{|c|c|}
\hline Multi-state & $\begin{array}{l}f_{0}\left(i, j, k_{c s}, k_{c s d}, k_{c f}, n\right)= \\
=\sum_{a=1}^{\min \left(k_{c f}, n\right)-1} p_{0}^{a} \cdot\left[f_{1}\left(i, j, k_{c s}, k_{c s d}, k_{c f}, n-a\right)+f_{2}\left(i, j, k_{c s}, k_{c s d}, k_{c f}, n-a\right)\right] \\
f_{1}\left(i, j, k_{c s}, k_{c s d}, k_{c f}, n\right)= \\
=\sum_{b=1}^{\min \left(k_{c s d}-1, n\right)} \sum_{i^{\prime}=0}^{b} P\left\{T_{b s}=i^{\prime}, T_{b d}=b-i^{\prime}, L_{b s}<k_{c s}, X_{b}=1 \mid T_{b f}=0\right\} \cdot h_{0}\left(i, i^{\prime}, j, b\right) \\
=\sum_{c=1}^{\min \left(k_{c s d}-1, n\right)} \sum_{i^{\prime}=0}^{c} P\left\{T_{c s}=i^{\prime}, T_{c d}=c-i^{\prime}, L_{c s}<k_{c s}, X_{c}=2 \mid T_{c f}=0\right\} \cdot h_{0}\left(i, i^{\prime}, j, c\right) \\
h_{0}\left(i, i^{\prime}, j, m\right)=P\left\{T_{m f}=0\right\} \cdot f_{0}\left(i-i^{\prime}, j-\left(m-i^{\prime}\right), k_{c s}, k_{c s d}, k_{c f}, n-m\right)\end{array}$ \\
\hline Weighted & $\begin{array}{c}\text { For } S_{n} \geq i \geq 1, S_{n} \geq j \geq 1 \\
f_{0}(i, j, n)=\sum_{a=1}^{n-1}\left\{\left(\prod_{r=n-a+1}^{n} q_{r}\right) \cdot u\left[\min \left(j, k_{c w f}-1\right)-S(a, n)\right] \cdot f_{1}(i, j-S(a, n), n-a)\right\} \\
f_{1}(i, j, n)=\sum_{b=1}^{n-1}\left\{\left(\prod_{t=n-b+1}^{n} p_{t}\right) \cdot u\left[\min \left(i, k_{c w s}-1\right)-S(b, n)\right] \cdot f_{0}(i-S(b, n), j, n-b)\right\} \\
\text { where } \\
S(c, n)=\sum_{r=n-c+1}^{n} w(r)\end{array}$ \\
\hline Planar & $\begin{array}{c}i \geq 1, n>1: \\
f(i, 1, n)=\sum_{a=1}^{\min \left(k_{c f}, n\right)-1} q^{M a} \sum_{j^{\prime}>1} f\left(i, j^{\prime}, n-a\right) \cdot u[M(n-a)-i] \\
i \geq 1, n>1: \\
f\left(i, 2^{M}, n\right)=\sum_{b=1}^{\min \left(k_{c s}, n\right)-1} p^{M b} \sum_{j^{\prime}<2^{M}} f\left(i-M b, j^{\prime}, n-b\right)+p^{M n} \cdot u\left[k_{c s}-1-n\right] \cdot \delta[i-M n] \\
F o r 1<j<2^{M}, n>1: \\
f(i, j, n)=p^{\left\|\underline{V}_{j}\right\|} q^{M-\left\|\underline{V}_{j}\right\|} \cdot \sum_{j^{\prime}=1}^{2^{M}} f\left(i-\left\|\underline{V}_{j}\right\|, j^{\prime}, n-1\right)\end{array}$ \\
\hline
\end{tabular}

Some reasonable boundary conditions were added to these sets of difference equations. 
International Journal of Mathematical, Engineering and Management Sciences

Vol. 3, No. 3, 195-219, 2018

https://dx.doi.org/10.33889/IJMEMS.2018.3.3-015

\section{The Probability Functions}

Using the auxiliary functions and referring to Tables 1, 2 the following probability functions are then derived.

a. For binary tests (TSCSTFCF):

$$
\begin{aligned}
& P\{N \geq n\}=\sum_{i=\max }^{k_{s}-1}\left[f_{0}\left(i, k_{f s}, k_{c f}, n\right)+f_{1}\left(i, k_{c s}, k_{c f}, n\right)\right] \\
& P_{a, 1}=\sum_{n=k_{s}}^{\infty} P\left\{T_{n, s}=k_{s}, L_{n, s}<k_{c s}, T_{n, f}<k_{f}, L_{n, f}<k_{c f}, X_{n}=1\right\}= \\
& =\sum_{n=k_{s}}^{k_{s}+k_{f}-1} f_{1}\left(k_{s}, k_{c s}, k_{c f}, n\right) \\
& P_{a, 2}=p_{1} \cdot \prod_{j=1}^{k_{c s}-1} c_{k_{c s}-j, n-j+1} \cdot \delta\left[n-k_{c s}\right]+q_{1} \cdot \prod_{j=1}^{k_{c s}} c_{k_{c s}-j, n-j+1} \cdot \delta\left[n-k_{c s}-1\right] \\
& +\sum_{n=k_{c s}+2}^{k_{s}+k_{f}-1} \sum_{i=\max }^{n}\left(\prod_{c s s}^{n}, n-k_{f}+1\right)\left(\prod_{j=1}^{k_{c s}} c_{i-j, n-j+1}\right) \cdot f_{0}\left(i-k_{c s}, k_{c s}, k_{c f}, n-k_{c s}\right)
\end{aligned}
$$

b. For multi-state tests:

$$
P\{N \geq n\}=\sum_{i=0}^{\min \left(k_{s}-1, n\right)} \sum_{j=\max \left(0, n-k_{f}-i+1\right)}^{\min \left(k_{s d}-i-1, n\right)} \sum_{r=0}^{2} f_{r}\left(i, j, k_{c s}, k_{c s d}, k_{c f}, n\right)
$$

Instead of evaluating $P_{a, 1}, P_{a, 2}$, it is more convenient to handle the probabilities of rejection $P_{r, 1}$, $P_{r, 2}$ :

$$
P_{r 1}=\sum_{n=k_{f}}^{\infty} P\left\{T_{n f}=k_{f}, L_{n f}<k_{c f}, T_{n s}<k_{s}, L_{n s}<k_{c s}, T_{n d}<k_{d}, L_{n s d}<k_{c s d}, X_{n}=0\right\}
$$

In terms of the previously defined functions,

$$
P_{r 1}=\sum_{n=k_{f}}^{\infty} \sum_{\substack{k_{s d}>i+j=n-k_{f} \\ k_{s}>i}} f_{0}\left(i, j, k_{c s}, k_{c s d}, k_{c f}, n\right)
$$

The probability of having the second possibility is 
International Journal of Mathematical, Engineering and Management Sciences

Vol. 3, No. 3, 195-219, 2018

https://dx.doi.org/10.33889/IJMEMS.2018.3.3-015

$$
P_{r 2}=\sum_{i, j, n} P\left\{T_{n s}=i, T_{n d}=j, T_{n f}<k_{f}, L_{n s}<k_{c s}, L_{n s d}<k_{c s d}, L_{n f}=k_{c f}, L_{n-1, f}<k_{c f}\right\}
$$

Summing up on the relevant $f$ functions,

$$
P_{r 2}=p_{0} k_{c f} \sum_{n=k_{c f}}^{\infty} \sum_{i=\max \left(0, n-k_{f}-k_{s d}+1\right)}^{\min \left(n-k_{c f}, k_{s}-1\right)} \sum_{j=\max \left(0, n-k_{f}-i\right)}^{k_{c c s}-i-1}\left[f_{1}\left(i, j, k_{c s}, k_{c s d}, k_{c f}, n-k_{c f}\right)+f_{2}\left(i, j, k_{c s}, k_{c s d}, k_{c f}, n-k_{c f}\right)\right]
$$

and

$$
P_{r}=P_{r 1}+P_{r 2}
$$

The probability of acceptance is simply

$$
P_{a}=1-P_{r}
$$

c. Considering the procedure for distant failures (TSCSTFDF):

$$
P\{N \geq n\}=\sum_{i=\max }^{k_{s}-1}\left[f_{0}(i, n)+f_{f}(i, n)\right]
$$

The first term contribution to $P_{a}$ is:

$$
P_{a, 1}=\sum_{n=k_{s}}^{k_{s}+k_{f}-1} f_{1}\left(k_{s}, n\right)
$$

and the second is:

$$
\begin{aligned}
P_{a, i, n} & =P\left\{T_{n, s}=i, L_{n, s}=k_{c s}, L_{n-1, s}<k_{c s}, T_{n, f}<k_{f}, D_{n f}>r-2\right\} \\
P_{a, 2} & =\sum_{n=k_{c s}}^{k_{s}+k_{f}-1} \sum_{i} P_{a, i, n} \\
& =p^{k_{c s}} \cdot \delta\left[n-k_{c s}\right]+q p^{k_{c s}} \cdot \delta\left[n-k_{c s}-1\right]+\sum_{n=k_{c s}+2 i=\max }^{k_{s}+k_{f}-1} \sum_{\left.0, k_{f}+1, k_{c s}\right)}^{\min \left(n, k_{s}\right)} p_{c s}^{k_{c s}} \cdot f_{0}\left(i-k_{c s}, n-k_{c s}\right)
\end{aligned}
$$


International Journal of Mathematical, Engineering and Management Sciences

Vol. 3, No. 3, 195-219, 2018

https://dx.doi.org/10.33889/IJMEMS.2018.3.3-015

d. For the procedure with weighted tests TSCSTFCF $_{w}$ :

$$
\begin{aligned}
& P\{N>n\}=\sum_{i=0}^{\min \left(k_{w s}-1, S_{n}\right)} \sum_{j=0}^{\min \left(k_{w f}-1, S_{n}\right)}\left[f_{0}(i, j, n)+f_{1}(i, j, n)\right] \\
& P_{a, 1, n}=P\left\{T_{n w s} \geq k_{w s}, T_{n-1, w s}<k_{w s}, L_{n w s}<k_{c w s}, T_{n w f}<k_{w f}, L_{n w f}<k_{c w f}\right\} \\
& P_{a, 2, n}=P\left\{T_{n w s} \leq k_{w s}, T_{n-1, w s}<k_{w s}, L_{n w s}=k_{c w s}, L_{n-1, w s}<k_{c w s}, T_{n w f}<k_{w f}, L_{n w f}<k_{c w f}\right\}
\end{aligned}
$$

and in relation to the definition of auxiliary functions:

$$
P_{a, 1, n}=\sum_{j=0}^{k_{w f}-1} f_{1}\left(k_{w s}, j, n\right)
$$

For $n>1$ :

$$
P_{a, 2, n}=\sum_{i=\max \left(0, S_{n}-k_{w f}, k_{c w s}\right)}^{\min \left(S_{n}, k_{w s}\right)} \sum_{j=0}^{k_{w f}-1_{n=0}^{n-1}} \sum_{r=0} g(i, j, r, n)
$$

where

$$
\begin{aligned}
& g(i, j, r, n)=\left(\prod_{s=0}^{r} p_{n-s}\right) \cdot u\left[S(r+1, n)-k_{c w s}\right] \cdot u\left[\left(k_{c w s}-1\right)-S(r, n-1)\right] \cdot u[(n-1)-(r+1)] \cdot \\
& u\left[\left(k_{w s}-1\right)-(i-w(n))\right] f_{0}(i-S(r+1, n), j, n-(r+1))+\left(\prod_{s=0}^{n-1} p_{n-s}\right) \cdot \delta[n-(r+1)] \cdot \delta[j] \cdot \delta\left[i-S_{n}\right]
\end{aligned}
$$

e. The extension to the planar case yields (testing $M$ units in parallel):

$$
\begin{aligned}
& P\{N>n\}=\sum_{i=\max }\left(\sum_{\left.M n-k_{f}+1,0\right)}^{\min } \sum_{j=1}^{\left.k_{s}-1, M n\right)} f(i, j, n)\right. \\
& P_{a, 1, n}=P\left\{T_{n, s} \geq k_{s}, T_{n-1, s}<k_{s}, T_{n, f}<k_{f}, R_{M, n, s}<M k_{c s}, R_{M, n, f}<M k_{c f}\right\}
\end{aligned}
$$

and

$$
P_{a, 2, n}=P\left\{\text { any } T_{n, s}, R_{M, n-1, s}<M k_{c s}, R_{M, n, s}=M k_{c s}, T_{n, f}<k_{f}, R_{M, n, f}<k_{c f}\right\}
$$


International Journal of Mathematical, Engineering and Management Sciences

Vol. 3, No. 3, 195-219, 2018

https://dx.doi.org/10.33889/IJMEMS.2018.3.3-015

It turns out that

$$
P_{a, 1, j, n}=\sum_{i=\max \left(k_{s}-1, M n-k_{f}\right)+1}^{k_{s}+\left\|\underline{X}_{n}\right\|-1} f(i, j, n)
$$

and

$$
\begin{aligned}
& P_{a, 1}=\sum_{n=1}^{\infty} \sum_{j=2}^{2^{M}} P_{a, 1, j, n} \\
& P_{a, 2, i, n}=p^{M k_{c s}} \cdot \sum_{j=1}^{2^{M}-1} f\left(i-M k_{c s}, j, n-k_{c s}\right)
\end{aligned}
$$

so that

$$
P_{a, 2}=\sum_{n=k_{c s}}^{\infty} \sum_{i=\max \left(0, M n-k_{f}+1, M k_{c s}\right)}^{\min \left(k_{s}+M-1, M n\right)} P_{a, 2, i, n}
$$

\section{The Optimization Problem}

As mentioned above, two important functions of interest are - the expected number of required tests $(E\{N\})$ and the probability of acceptance of the tested equipment $\left(P_{a}\right)$. Actually, we choose two values of probability, an upper $p_{U}$ value and a lower $p_{L}$ value. Then, the tested unit is accepted if the probability of success $p$ of each individual test is higher than $p_{U}$ and it is rejected if it is lower than $p_{L}$. This sets up a confidence level on the acceptance of the tested equipment and we consider here the two types of error for acceptance: Type I (rejection when $p>p_{U}$,) and Type II (acceptance when $p<p_{L}$ ).

Considering the basic TSCSTFCF procedure, the optimization problem to be handled is the minimization of the number of required tests (through minimizing their expected number) subject to the above mentioned confidence limits on the probability of acceptance. Explicitly, determine the values of $k_{s}, k_{c s}, k_{f}, k_{c f}$ so that they will minimize $\mathrm{E}\{N\}$ together with satisfying the inequalities (30) on the probability of acceptance:

$$
\begin{aligned}
& P\left\{a / p=p_{U}\right\}>1-\beta \\
& P\left\{a / p=p_{L}\right\}<\alpha
\end{aligned}
$$

It is problematic to provide a closed-form solution even in the simplest cases of TSTF or CSCF procedures. This is due to the fact that the unknowns appear as exponents within the above inequalities and normally there don't exist simple closed-form expressions for their solution.

The optimization problem may be solved in various ways like using generating functions or with aid of the Markov Chain Embedding technique. Here we present an approach based on the above 
International Journal of Mathematical, Engineering and Management Sciences

Vol. 3, No. 3, 195-219, 2018

https://dx.doi.org/10.33889/IJMEMS.2018.3.3-015

evaluated probability functions. It has been seen to be rather simple and easy to implement for purpose of calculations. At first this technique has been applied to the case of i.i.d. binary tests. Further, on extensions to dependent and multi-state tests have been carried out. Also the parameters of various other procedures (mentioned above) like TSCSTFDF (distant failures) and the weighted TSCSTFCF have been optimized using the same approach. Finally, the optimization problem has been extended to a two-dimensional TSCSTFCF procedure based on the same technique.

\section{General Results}

Numerical results have been obtained for the values of the various parameters involved in each procedure, the minimal expected number of required tests (together with its standard deviation value $S d\{N\}$ ) and the probabilities of acceptance for the upper and lower probability values $p_{U}, p_{L}$. Obviously, these are dependent on the required level of confidence $(\alpha, \beta)$. We summarize those results within Tables 4 to 8 . The calculation time of the optimum is also an important factor and therefore it is added within these tables (see also Zhao et al., 2010). In some cases it has been observed that the calculations were significantly shorter by using the present approach when compared to those using the Markov Chain Embedding technique (MCE). Also, since the MCE involves the inversion of large matrices, it can't be accomplished in a simple way. An example is presented in Table 7 where it seems that the only way for a solution is by using the combinatorial approach.

Table 4. Optimal values of the expected number of tests for different procedures $\alpha=0.05, \beta=0.05, p_{U}=0.9, p_{L}=0.6$

\begin{tabular}{|c|c|c|c|c|c|}
\hline No. & Procedure & $E\{N\}$ & $S d\{N\}$ & Parameter values & $\begin{array}{l}\text { CPU time } \\
\quad(\mathrm{sec})\end{array}$ \\
\hline & CSTF & 17.75 & 8.94 & $k_{c s}, k_{f}=10,7$ & 5.04 \\
\hline 1 & TSCSTFCF(binary,i.i.d.) & 15.69 & 5.57 & $k_{s}, k_{c s}, k_{f}, k_{c f}=20,10,6,3$ & 6.05 \\
\hline 2 & $\begin{array}{c}\text { TSCSTFCF(dependent) } \\
\theta_{n} \leq 0.1\end{array}$ & 17.19 & 8.75 & $\begin{array}{c}k_{s}, k_{c s}, k_{f}, k_{c f}= \\
32,10,8,3\end{array}$ & 5.04 \\
\hline \multirow[t]{2}{*}{3} & $\begin{array}{c}\text { TSCSTFCF(multi-state) } \\
p_{e}=0.5\end{array}$ & 19.10 & 3.58 & $\begin{array}{c}k_{s}, k_{c s}, k_{s d}, k_{c s d}, k_{f}, k_{c f}= \\
14,10,19,14,6,3 \\
\end{array}$ & 18.92 \\
\hline & $\begin{array}{c}\text { TSCSTFDF } \\
\text { (distant failures) }\end{array}$ & - & - & & \\
\hline 4 & $\begin{array}{c}\text { (weighted) TSCSTFCF } \\
w_{10}=2\end{array}$ & 15.95 & 6.13 & $\begin{array}{c}k_{w s}, k_{w c s}, k_{w f}, k_{w c f}= \\
22,11,7,3\end{array}$ & 8.84 \\
\hline \multirow[t]{3}{*}{5} & $\begin{array}{c}\text { (weighted) } \mathrm{TSCSTFCF}_{\mathrm{W}} \\
w_{1}=w_{19}=w_{22}=2\end{array}$ & 14.90 & 6.36 & $\begin{array}{c}k_{w s}, k_{w c s}, k_{w f}, k_{w c f}= \\
25,10,7,3\end{array}$ & 7.63 \\
\hline & $\begin{array}{l}\text { Planar TSCSTFCF } \\
\text { (binary,i.i.d.) }(M=2)\end{array}$ & 8.14 & 2.91 & $k_{s}, k_{c s}, k_{f}, k_{c f}=20,5,6,2$ & 6.31 \\
\hline & $\begin{array}{l}\text { Planar TSCSTFCF } \\
\text { (binary,i.i.d.) }(M=5)\end{array}$ & 3.54 & 1.33 & $\begin{array}{c}k_{s}, k_{c s}, k_{f} k_{c f}= \\
20,2,7, \infty\end{array}$ & 5.49 \\
\hline
\end{tabular}


International Journal of Mathematical, Engineering and Management Sciences

Vol. 3, No. 3, 195-219, 2018

https://dx.doi.org/10.33889/IJMEMS.2018.3.3-015

The second row in Table 4 presents improved results in comparison to those shown in a previous paper (Gera, 2011). The procedure that involves a third state (not binary) requires a relative long CPU time to arrive at an optimum compared to the rather short calculation time needed for the binary state procedures. As for the distant failures model, it was impossible to find parameters that will cope with the constraints. It is thus assumed that an optimum doesn't exist.

The weighted procedure is observed to yield the least time consuming a set of tests (for testing a single unit). Regarding the planar case and as anticipated, the more units we test in parallel, the larger the saving in the time durance of those tests. The standard deviation shrinks as well.

Table 5.Optimal values of the expected number of tests for different procedures

$$
\alpha=0.05, \beta=0.15, p_{U}=0.9, p_{L}=0.6
$$

\begin{tabular}{|c|c|c|c|c|c|}
\hline No. & Procedure & $E\{N\}$ & $S d\{N\}$ & Parameter values & $\begin{array}{l}\text { CPU time } \\
(\mathrm{sec})\end{array}$ \\
\hline & CSTF & 12.36 & 4.80 & $k_{c s}, k_{f}=9,5$ & 6.5 \\
\hline 1 & TSCSTFCF(binary,i.i.d.) & 11.62 & 3.53 & $\begin{array}{c}k_{s}, k_{c s}, k_{f}, k_{c f}= \\
14,9,4,2\end{array}$ & 4.7 \\
\hline 2 & $\begin{array}{c}\text { TSCSTFCF(dependent) } \\
\theta_{n} \leq 0.1\end{array}$ & 15.05 & 5.35 & $\begin{array}{c}k_{s}, k_{c s}, k_{f}, k_{c f}= \\
20,10,5,3\end{array}$ & 6.5 \\
\hline \multirow[t]{2}{*}{3} & $\begin{array}{c}\text { TSCSTFCF(multi-state) } \\
p_{e}=0.5\end{array}$ & 13.39 & 2.54 & $\begin{array}{c}k_{s}, k_{c s}, k_{s d}, k_{c s d}, k_{f}, k_{c f}= \\
12,9,13,13,4,2\end{array}$ & 9.0 \\
\hline & $\begin{array}{c}\operatorname{CSDF}(r=2) \\
\text { (distant failures) }\end{array}$ & 13.81 & 7.75 & $\begin{array}{c}k_{c s}, r= \\
9,2\end{array}$ & 8.2 \\
\hline 4 & $\begin{array}{c}\text { (weighted) TSCSTFCF } \\
w_{10}=2\end{array}$ & 13.01 & 2.87 & $\begin{array}{c}k_{w s}, k_{w c s}, k_{w}, k_{w c c}= \\
15,11,4,3\end{array}$ & 6.0 \\
\hline \multirow[t]{3}{*}{5} & $\begin{array}{c}\text { (weighted) TSCSTFCF } \\
w_{l}=w_{19}=w_{22}=2\end{array}$ & 13.55 & 4.56 & $\begin{array}{c}k_{w s}, k_{w c s}, k_{w f}, k_{w c f}= \\
18,10,5,3\end{array}$ & 8.9 \\
\hline & $\begin{array}{l}\text { Planar TSCSTFCF } \\
\text { (binary,i.i.d.) }(M=2)\end{array}$ & 6.79 & 3.54 & $\begin{array}{c}k_{s}, k_{c s}, k_{f}, k_{c f}= \\
14,5,4,2\end{array}$ & 5.6 \\
\hline & $\begin{array}{l}\text { Planar TSCSTFCF } \\
\text { (binary,i.i.d.) }(M=5)\end{array}$ & 2.76 & 0.66 & $\begin{array}{c}k_{s}, k_{c s}, k_{f}, k_{c f}= \\
13,2,4,2\end{array}$ & 6.1 \\
\hline
\end{tabular}

In general, the loosening of the restriction on the confidence level yields lower values of the optimal $E\{N\}$, and thus shortens the time of the testing. It is observed that the lowest value is achieved by using the binary TSCSTFCF procedure.

The CPU time for the CSTF plan is longer than that of the more general TSCSTFCF plan due to applying the generally oriented program for that special case. 
International Journal of Mathematical, Engineering and Management Sciences

Vol. 3, No. 3, 195-219, 2018

https://dx.doi.org/10.33889/IJMEMS.2018.3.3-015

Table 6. Optimal values of the expected number of tests for different procedures $\alpha=0.05, \beta=0.25, p_{U}=0.9, p_{L}=0.6$

\begin{tabular}{|c|c|c|c|c|c|}
\hline No. & Procedure & $E\{N\}$ & $S d\{N\}$ & Parameter values & $\begin{array}{c}\text { CPU time } \\
(\mathrm{sec})\end{array}$ \\
\hline & CSTF & 10.46 & 3.34 & $k_{c s}, k_{f}=8,3$ & 6.4 \\
\hline 1 & TSCSTFCF(binary,i.i.d.) & 10.06 & 3.03 & $\begin{array}{c}k_{s}, k_{c s}, k_{f}, k_{c f}= \\
13,8,3,2\end{array}$ & 6.9 \\
\hline 2 & $\begin{array}{c}\text { TSCSTFCF(dependent) } \\
\theta_{n} \leq 0.1\end{array}$ & 11.34 & 2.96 & $\begin{array}{c}k_{s}, k_{c s}, k_{f}, k_{c f}= \\
13,10,3,2\end{array}$ & 6.1 \\
\hline 3 & $\begin{array}{c}\text { TSCSTFCF(multi-state) } \\
p_{e}=0.5\end{array}$ & 11.43 & 3.87 & $\begin{array}{c}k_{s}, k_{c s}, k_{s d}, k_{c s}, k_{f}, k_{c f}= \\
9,6,21,9,3,2\end{array}$ & 9.3 \\
\hline 4 & $\begin{array}{c}\text { TSCSTFDF } \\
\text { (distant failures) }\end{array}$ & 12.79 & 5.46 & $\begin{array}{c}k_{c s}, k_{f}, r= \\
9,4,2\end{array}$ & 5.8 \\
\hline 5 & $\begin{array}{c}\text { (weighted) TSCSTFCF } \\
w_{10}=2\end{array}$ & 11.06 & 2.37 & $\begin{array}{c}k_{w s}, k_{w c s}, k_{w f}, k_{w c}= \\
13,11,3,2\end{array}$ & 5.6 \\
\hline & $\begin{array}{c}\text { (weighted) TSCSTFCF } \\
w_{l}=w_{19}=w_{22}=2\end{array}$ & 10.76 & 4.66 & $\begin{array}{c}k_{w s}, k_{w c s}, k_{w f}, k_{w c}= \\
15,10,4,2\end{array}$ & 9.5 \\
\hline (binar TSCSTFCF \\
\hline $\begin{array}{c}\text { Planar TSCSTFCF } \\
\text { (binary,i.i.d.) }(M=5)\end{array}$ & 2.57 & 0.51 & $\begin{array}{c}k_{s}, k_{c s}, k_{f}, k_{c}= \\
13,2,3,2\end{array}$ & 5.4 \\
\hline
\end{tabular}

The compromise between the shortening of the testing time and the required confidence level is further observed here as the values of the optimum are even lower than in the previous table. Again, the binary TSCSTFCF procedure gives the minimal value of optimum. Calculation times are not essentially different from those of the previous cases.

Table 7.Optimal values of the expected number of tests for different procedures $\alpha=0.05, \beta=0.05, p_{U}=0.85, p_{L}=0.65$

\begin{tabular}{|c|c|c|c|c|c|}
\hline No. & Procedure & $E\{N\}$ & $S d\{N\}$ & Parameter values & $\begin{array}{c}\text { CPU time } \\
(\mathrm{sec})\end{array}$ \\
\hline $1\left(^{* *}\right)$ & CSTF & 78.55 & 57.87 & $k_{c s}, k_{f}=16,39$ & 9.7 \\
\hline 2 & \begin{tabular}{c} 
TSCSTFCF(binary,i.i.d.) \\
\hline
\end{tabular} & 43.25 & 14.23 & $\begin{array}{c}k_{s}, k_{c s}, k_{f}, k_{c f}= \\
45,16,15,4\end{array}$ & 6.5 \\
\hline 3 & $\begin{array}{c}\theta_{n} \leq 0.1 \\
\text { TSCSTFCF(multi-state) } \\
p_{e}=0.5\end{array}$ & 47.68 & 13.43 & $\begin{array}{c}k_{s}, k_{c s}, k_{f}, k_{c f}= \\
47,18,15, \infty\end{array}$ & 6.3 \\
\hline 4 & $\begin{array}{c}\text { TSCSTFDF } \\
\text { (weighted) TSCSTFCF } \\
w_{10}=2\end{array}$ & 43.12 & 13.98 & $\begin{array}{c}k_{w s}, k_{w c s}, k_{w f}, k_{w c f}= \\
45,17,15,4\end{array}$ & 40.7 \\
\hline 5 & $\begin{array}{c}\text { (weighted) TSCSTFCF } \\
w_{l}=w_{19}=w_{22}=2\end{array}$ & 44.00 & 18.72 & $\begin{array}{c}k_{w s}, k_{w c s}, k_{w f}, k_{w c}= \\
54,16,18,4\end{array}$ & 71.1 \\
\hline $\begin{array}{c}\text { Planar TSCSTFCF } \\
\text { (binary,i.i.d.) }(M=2)\end{array}$ & 22.35 & 6.98 & $\begin{array}{c}k_{s}, k_{c s}, k_{f}, k_{c f}= \\
45,8,15,4\end{array}$ & 5.8 \\
\hline $\begin{array}{c}\text { Planar TSCSTFCF } \\
\text { (binary,i.i.d.) }(M=5)\end{array}$ & 9.34 & 1.57 & $\begin{array}{c}k_{s}, k_{c s}, k_{f}, k_{c f}= \\
40,4,14,4\end{array}$ & 6.0 \\
\hline
\end{tabular}


International Journal of Mathematical, Engineering and Management Sciences

Vol. 3, No. 3, 195-219, 2018

https://dx.doi.org/10.33889/IJMEMS.2018.3.3-015

The confidence level interval has been squeezed from $\left(p_{U}, p_{L}\right)=(0.9,0.6)$ in Table 4 to $(0.85,0.65)$ in Table 7, with the same confidence level values. Evidently, the more restrictive requirements in this table yield much more time consuming sets of tests. Thus, the question of the compromise between the need for tight requirements and the durance time of the tests should be considered.

Regarding $\left(1^{*}\right)$, according to the Markov chain embedding approach, the optimal parameters in this case involve a large matrix of about $32000 \times 32000$ elements, which cannot be inverted in a simple way. Probably the only way of achieving the results in this case is by using the present combinatorial technique. This seems true also for the other procedures in this example.

The results in the first row (for CSTF) show an improvement with respect to those previously presented (Gera, 2011; Smith and Griffith, 2005) and likewise for the second row (TSCSTFCF). As to the multi-state procedure (third row), no values are given since it required a long computation time. Again, it seems that the distant failures procedure has no optimum in this case that copes with the constraints. Practically, it is a question whether to adopt a weighted procedure or to use the normal binary TSCSTFCF model. The planar model is observed to reduce the testing time nearly linearly with respect to the number of tested units $(M)$.

Table 8.Optimal values of the expected number of tests for different procedures $\alpha=0.05, \beta=0.15, p_{U}=0.95, p_{L}=0.75$

\begin{tabular}{|c|c|c|c|c|c|}
\hline No. & Procedure & $E\{N\}$ & $S d\{N\}$ & Parameter values & $\begin{array}{c}\text { CPU time } \\
(\mathrm{sec})\end{array}$ \\
\hline 1 & TSCSTFCF(binary,i.i.d.) & 20.18 & 3.13 & $\begin{array}{c}k_{s}, k_{c s}, k_{f}, k_{c f}= \\
21,19,3,2\end{array}$ & 6.3 \\
\hline 2 & $\begin{array}{c}\text { TSCSTFCF(dependent) } \\
\theta_{n} \leq 0.1\end{array}$ & 23.47 & 5.54 & $\begin{array}{c}k_{s}, k_{c s}, k_{f}, k_{c f}= \\
27,20,4,2\end{array}$ & 5.4 \\
\hline 3 & $\begin{array}{c}\text { TSCSTFCF(multi-state) } \\
p_{e}=0.5\end{array}$ & 20.99 & 3.01 & $\begin{array}{c}k_{s}, k_{c s}, k_{s d}, k_{c s,}, k_{f}, k_{c f}= \\
15,21,3,19,2,21\end{array}$ & 17.6 \\
\hline & $\begin{array}{c}\text { TSCSTFDF } \\
\text { (distant failures) }\end{array}$ & 17.92 & 6.16 & $\begin{array}{c}k_{s}, k_{c s}, k_{f}, r= \\
\infty, 14,3,2\end{array}$ & 5.2 \\
\hline 4 & $\begin{array}{c}\text { (weighted) TSCSTFCFW } \\
w_{10}=2\end{array}$ & 24.13 & 10.06 & $\begin{array}{c}k_{w s}, k_{w c s}, k_{w f}, k_{w c}= \\
45,17,5,4\end{array}$ & 23.7 \\
\hline 5 & $\begin{array}{c}\text { (weighted) TSCSTFCF } \\
w_{1}=w_{19}=w_{22}=2\end{array}$ & 20.57 & 7.51 & $\begin{array}{c}k_{w s}, k_{w c s}, k_{w f}, k_{w c}= \\
54,16,4,3\end{array}$ & 31.6 \\
\hline & $\begin{array}{c}\text { Planar TSCSTFCF } \\
\text { (binary,i.i.d.) }(M=2)\end{array}$ & 12.17 & 5.07 & $\begin{array}{c}k_{s}, k_{c s}, k_{f}, k_{c f}= \\
45,8,5,4\end{array}$ & 5.13 \\
\hline $\begin{array}{c}\text { Planar TSCSTFCF } \\
\text { (binary,i.i.d.) }(M=5)\end{array}$ & 5.15 & 0.95 & $\begin{array}{c}k_{s}, k_{c s}, k_{f}, k_{c f}= \\
25,4,4,2\end{array}$ & 12.2 \\
\hline
\end{tabular}

The effect of loosening the constraints on the testing time can be seen in the following Fig. 1 where it is assumed that $p_{U}=0.9, p_{L}=0.6$. Obviously, the more restrictive requirements demand more tests. The question of which procedure to use is evidently dependent on these restrictions. 
International Journal of Mathematical, Engineering and Management Sciences

Vol. 3, No. 3, 195-219, 2018

https://dx.doi.org/10.33889/IJMEMS.2018.3.3-015

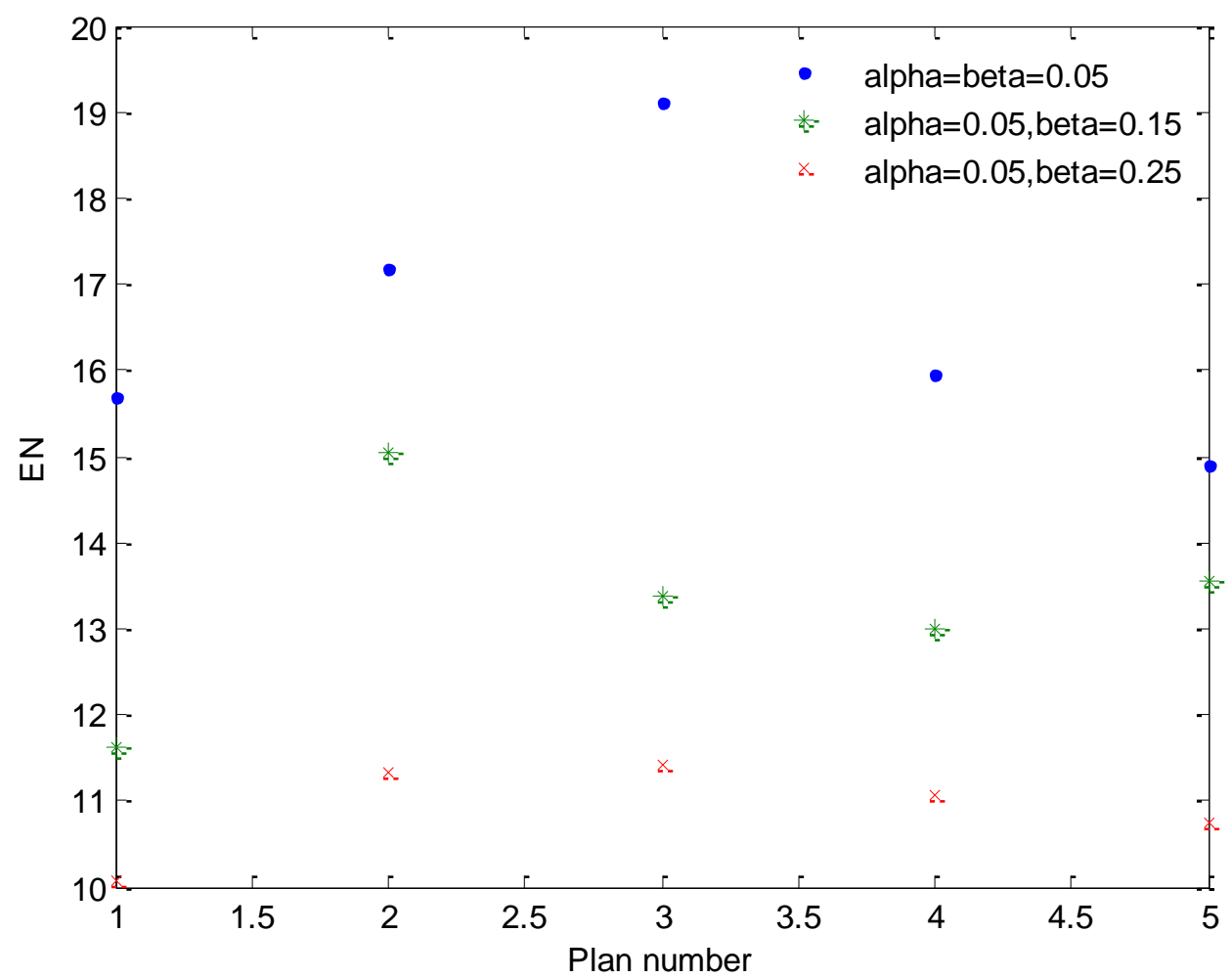

Fig. 1. The expected number of tests versus the plan number (Tables 4-6), $p_{U}=0.9, p_{L}=0.6$

\section{Additional Results}

At first, we wish to examine the rapidity of convergence of the series that is used for calculating $\mathrm{E}\{N\}$ (Zhao et al., 2015).

Let

$E_{K}\{N\}=\sum_{n=1}^{K} n \cdot P\{N=n\}$

Example A: CSTF, $\alpha=\beta=0.05, p_{U}=0.99, p_{L}=0.95$ (see Fig. 2 ) 
International Journal of Mathematical, Engineering and Management Sciences

Vol. 3, No. 3, 195-219, 2018

https://dx.doi.org/10.33889/IJMEMS.2018.3.3-015

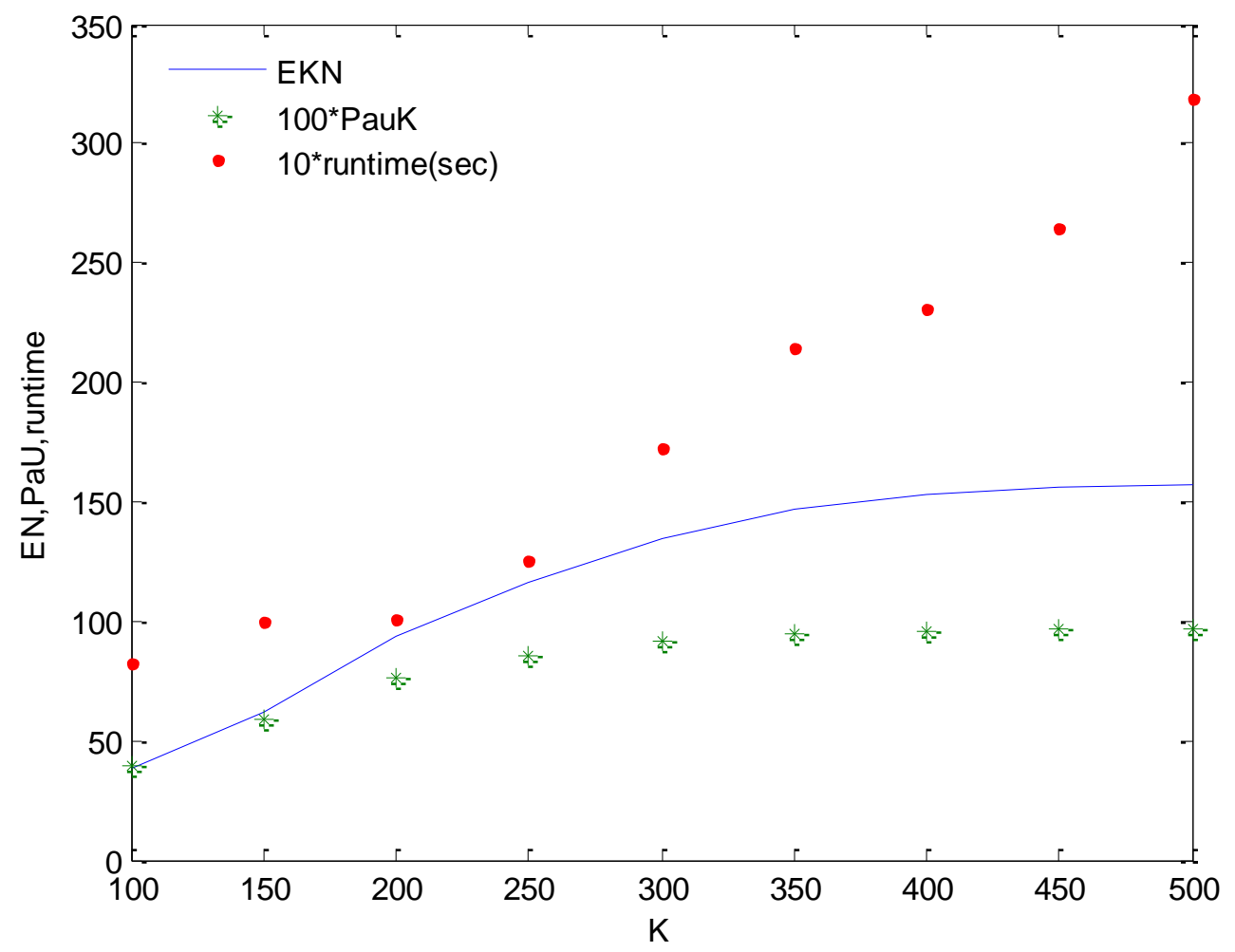

Fig. 2. $\mathrm{E}\{N\}, \mathrm{P}\{\mathrm{a}\}$ and runtime versus the upper limit $K(31)$ CSTF $, \alpha=\beta=0.05, p_{U}=0.99, p_{L}=0.95$

It turns out that we could actually stop the run around $K \sim 300$ with a rather low accuracy error.

Example B: TSCSTFCF : $\alpha=\beta=0.05, p_{U}=0.99, p_{L}=0.95$ (see Fig. 3) 
International Journal of Mathematical, Engineering and Management Sciences

Vol. 3, No. 3, 195-219, 2018

https://dx.doi.org/10.33889/IJMEMS.2018.3.3-015

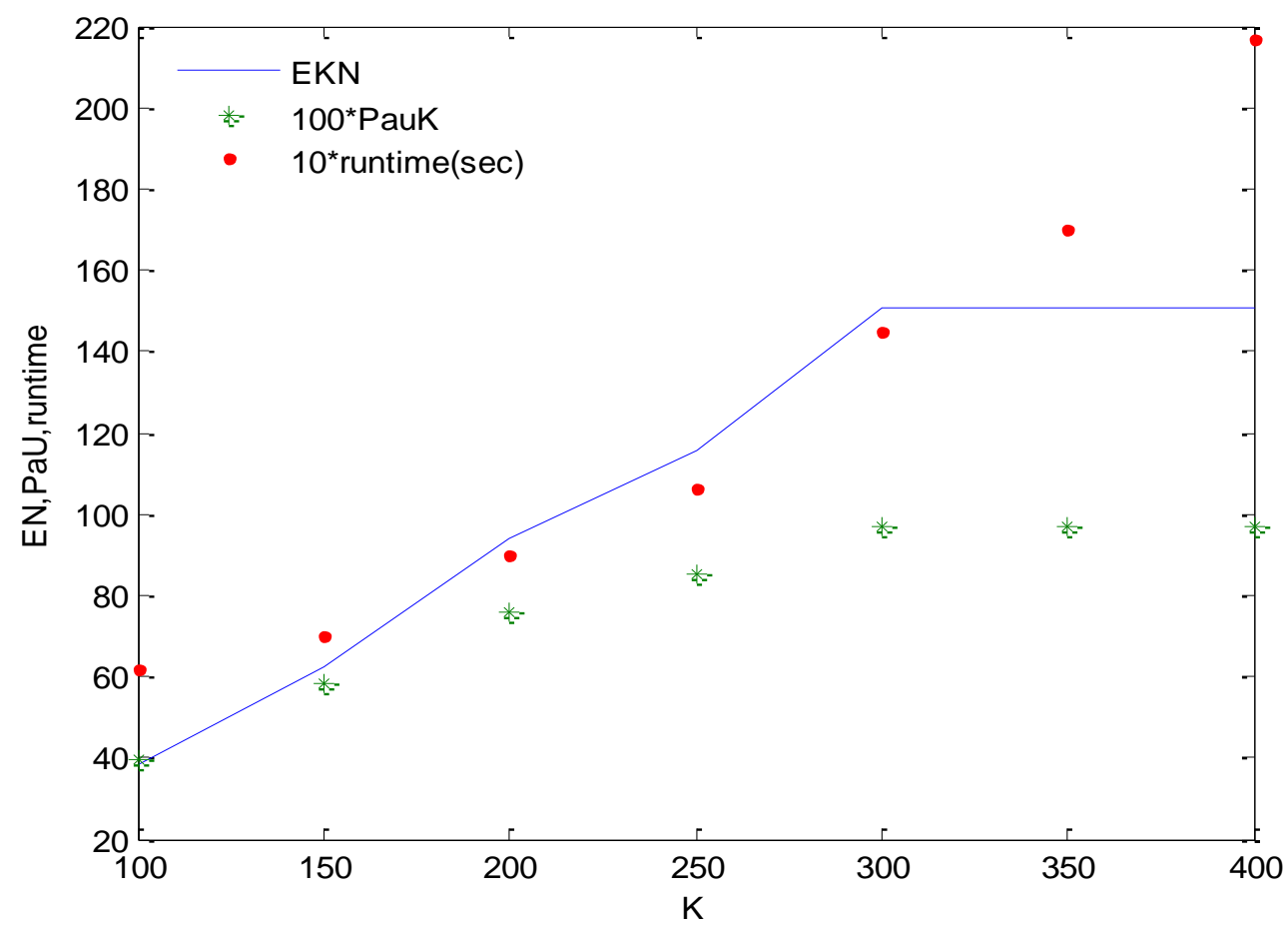

Fig. 3. E $\{N\}, P_{a, U}$ and runtime versus the upper limit $K(31)$ : TSCSTFCF : $\alpha=\beta=0.05, p_{U}=0.99, p_{L}=0.95$

Also in this case, the choice of $K=300$ will be satisfactory.

Often the question of the sensitivity of an optimum to variations in some of the variables is considered (Zhao et al., 2010). Some examples are now provided in relation to such variations.

Example C: TSCSTFCF, i.i.d., $\alpha=0.05, p_{U}=0.9, p_{L}=0.6$ :

The variation of the optimum with respect to changes in $\beta$ is presented in Table 9.

Table 9.Variation of the optimal $\mathrm{E}\{N\}$ versus changes in $\beta$

\begin{tabular}{|c|c|c|c|c|}
\hline$\beta$ & 0.05 & 0.1 & 0.15 & 0.25 \\
\hline CSTF E $\{N\}$ & 17.75 & 17.25 & 14.45 & 12.44 \\
\hline TSCSTFCF E $\{N\}$ & 15.69 & 14.64 & 11.62 & 10.06 \\
\hline
\end{tabular}

Evidently, loosening the restrictions on the confidence limits results in a lower expected number of required tests. 
International Journal of Mathematical, Engineering and Management Sciences

Vol. 3, No. 3, 195-219, 2018

https://dx.doi.org/10.33889/IJMEMS.2018.3.3-015

Example D: $\alpha=\beta=0.05, p_{U}=0.9$ :

The variation of the optimum with respect to changing $\mathrm{p}_{\mathrm{L}}$ is given in Table 10 .

Table 10.The variation in the optimal $\mathrm{E}\{N\}$ versus the discrimination factor

\begin{tabular}{|c|c|c|c|c|}
\hline$p_{L}$ & 0.5 & 0.6 & 0.7 & 0.8 \\
\hline$p_{U} / p_{L}$ & 1.8 & 1.5 & 1.29 & 1.13 \\
\hline TSCSTFCF $\mathrm{E}\{N\}$ & 9.89 & 15.69 & 33.14 & 121.6 \\
\hline
\end{tabular}

Again, the shrinking of the confidence interval will need much more tests.

Varying each of the parameters, its effect on the expected number of tests is now analyzed. For this sake, we will observe normalized values of the various parameter variations and of $\mathrm{E}\{N\}$.

Example E: TSCSTFCF, $p_{U}=0.9, p_{L}=0.6, \alpha=0.05, \beta=0.05$

The variation of $\mathrm{E}\{N\}$ and $P_{a}$ with respect to the four parameter variations are presented within Fig. 4 and Fig. 5.

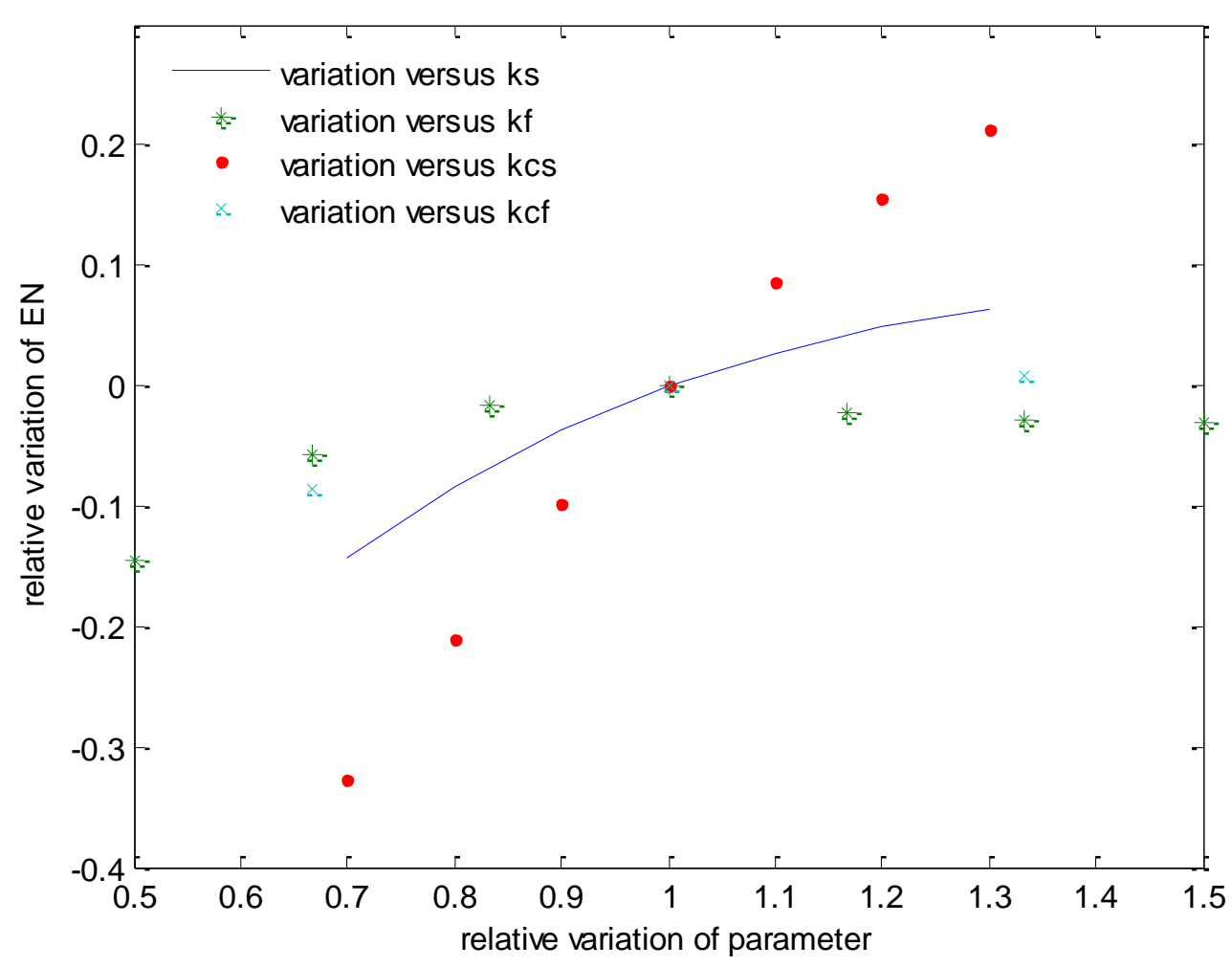

Fig. 4. The relative variation of $\mathrm{E}\{N\}$ with respect to changes in the parameters TSCSTFCF $, p_{U}=0.9, p_{L}=0.6, \alpha=0.05, \beta=0.05$ 
International Journal of Mathematical, Engineering and Management Sciences

Vol. 3, No. 3, 195-219, 2018

https://dx.doi.org/10.33889/IJMEMS.2018.3.3-015

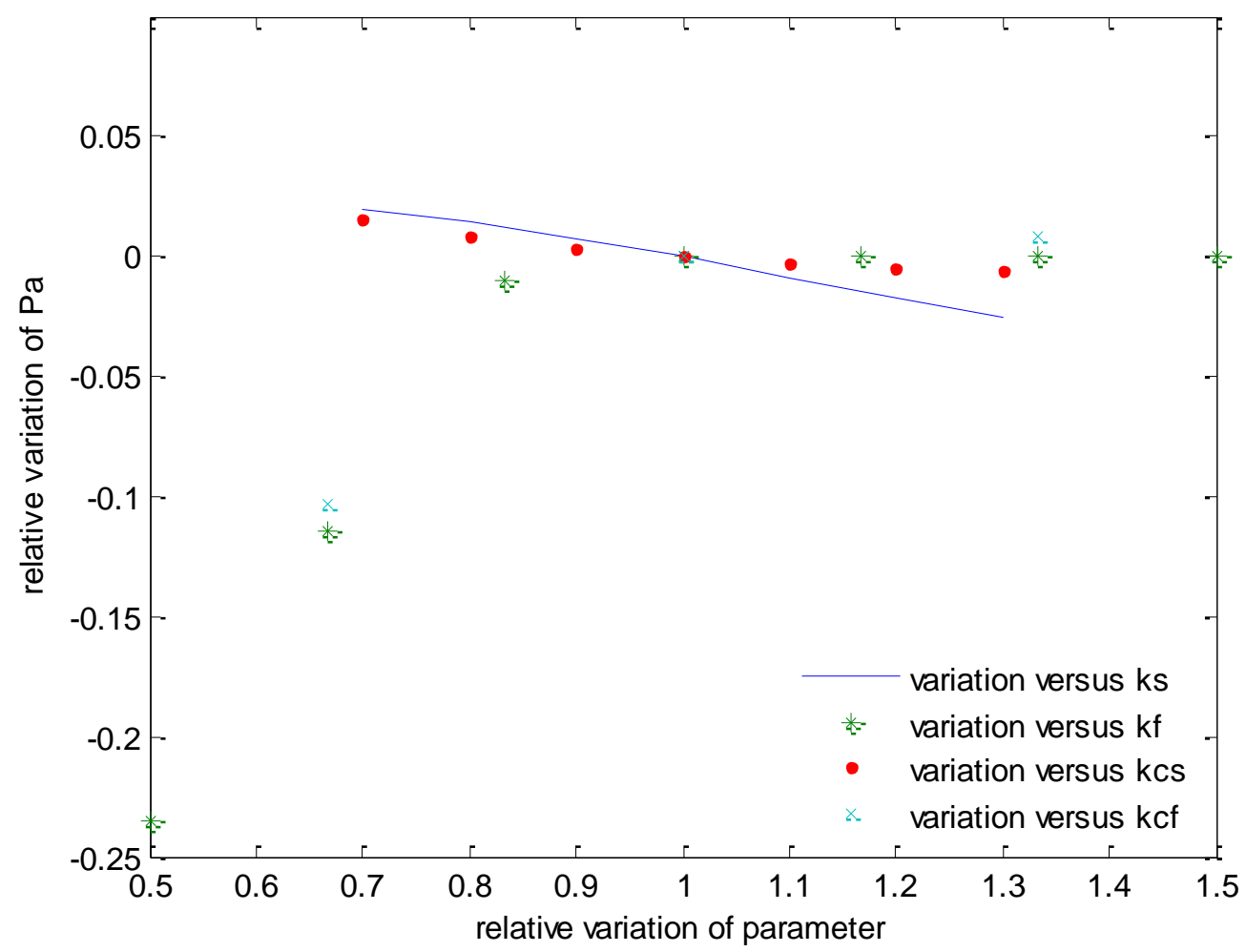

Fig. 5. The relative variation of $P_{a}$ with respect to parameter variations TSCSTFCF, $p_{U}=0.9, p_{L}=0.6, \alpha=0.05, \beta=0.05$

It is thus observed that $\mathrm{E}\{N\}$ is more sensitive to $k_{c s}$ variations whereas $P_{a}$ is mostly sensitive to changes in $k_{c f}$ and $k_{f}$ in this case.

Example F: The weighted procedure with $w(1)=w(19)=w(22)=2$ (see Fig. 6 and Fig. 7) 
International Journal of Mathematical, Engineering and Management Sciences

Vol. 3, No. 3, 195-219, 2018

https://dx.doi.org/10.33889/IJMEMS.2018.3.3-015

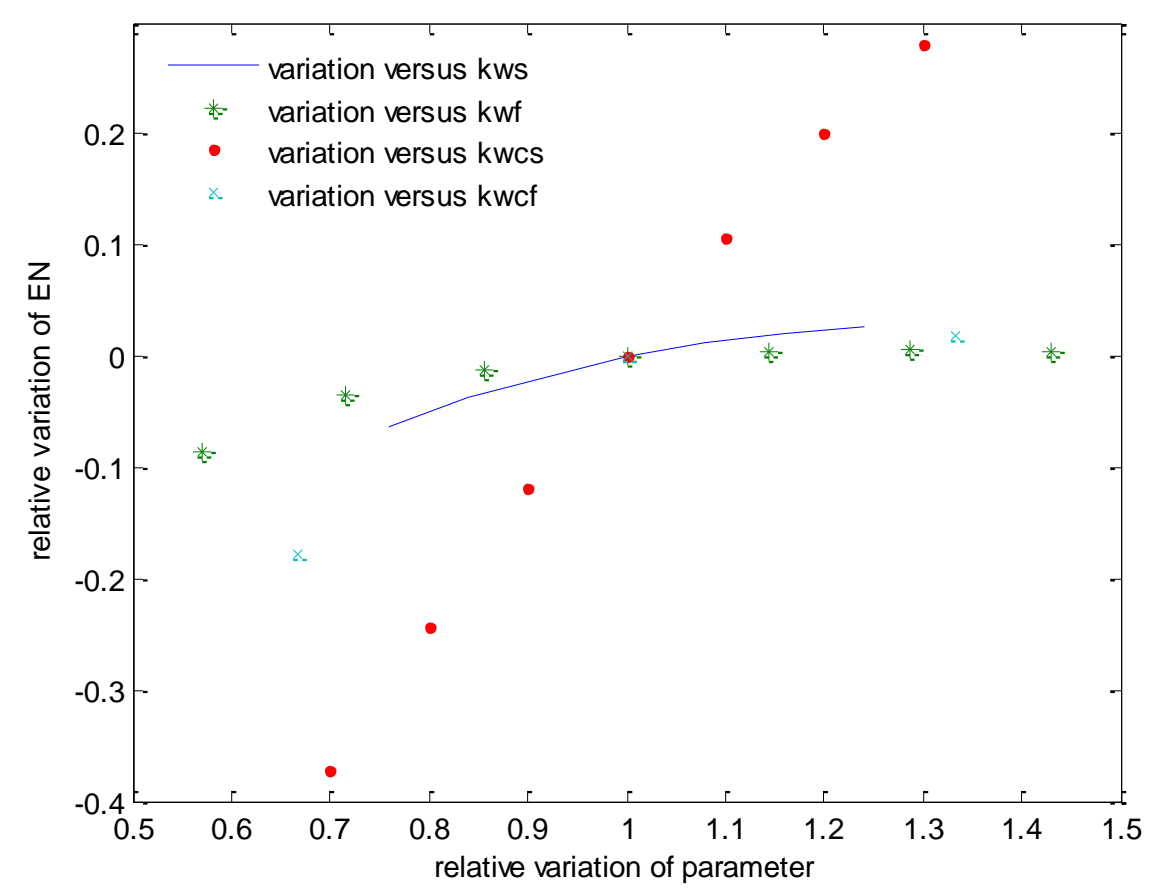

Fig. 6. The relative variation of $\mathrm{E}\{N\}$ with respect to changes in the parameters: weighted procedure with $w(1)=w(19)=w(22)=2$

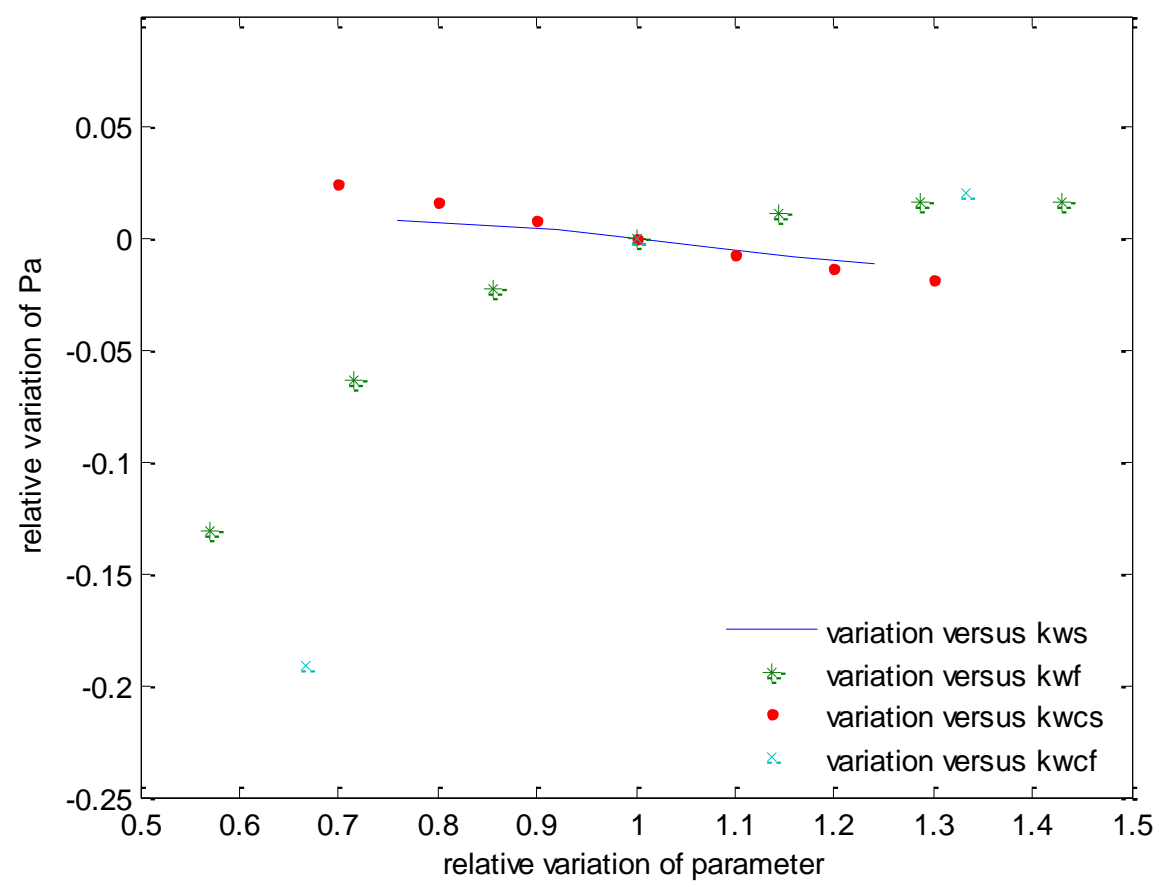

Fig. 7. The relative variation of $P_{a}$ with respect to changes in the parameters: weighted procedure with $w(1)=w(19)=w(22)=2$ 
International Journal of Mathematical, Engineering and Management Sciences

Vol. 3, No. 3, 195-219, 2018

https://dx.doi.org/10.33889/IJMEMS.2018.3.3-015

In this case, the dominant changes in $\mathrm{E}\{N\}$ are due to variations in $k_{w c s}$ whereas the $P_{a}$ function is more dominated by changes in $k_{w f}, k_{c w f}$.

The variations due to changes in the choice of $p_{U}, p_{L}$ are now considered. Actually, it seems preferable to discuss the changes versus the discrimination factor $p_{U} / p_{L}$. Obviously, the more we 'squeeze' the discrimination interval, the more tests are required.

Example G: The required number of tests when we shrink the confidence interval from $\left(p_{U}=0.9\right.$, $\left.p_{L}=0.6\right)$ to $\left(p_{U}=0.85, p_{L}=0.65\right) ; \alpha=0.05, \beta=0.05$ (see Fig. 8 )

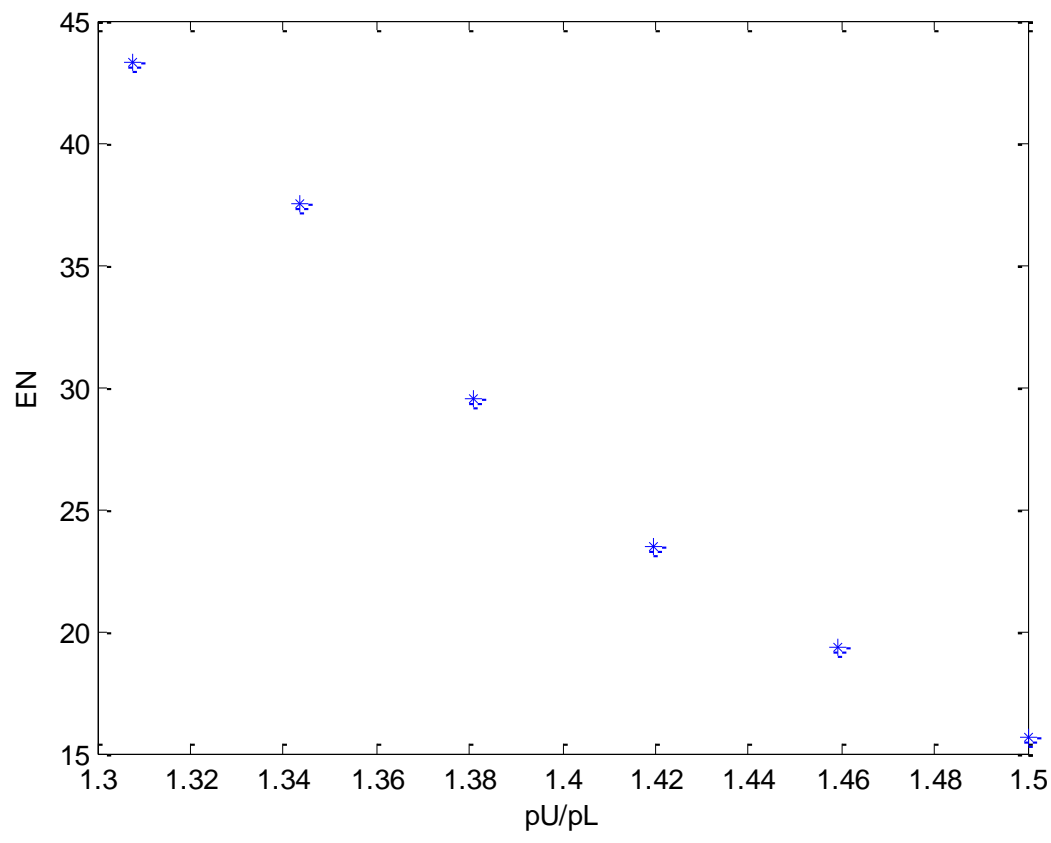

Fig. 8. The required expected number of tests versus the discrimination factor: $\left(p_{U}=0.9, p_{L}=0.6\right)$ to $\left(p_{U}=0.85, p_{L}=0.65\right) ; \alpha=0.05, \beta=0.05$

\section{Conclusion}

A comparison of procedures based on the combinatorial approach for handling start-up demonstration tests has been presented. The expected number of required tests and the probability of accepting the tested unit are derived using a set of auxiliary functions. A constrained optimization problem is solved for minimizing the number of required tests subject to some confidence level requirements. The variables for this optimization include the total number of successes, failures, and the maximal lengths of runs of successes and failures. 
International Journal of Mathematical, Engineering and Management Sciences

Vol. 3, No. 3, 195-219, 2018

https://dx.doi.org/10.33889/IJMEMS.2018.3.3-015

At first, i.i.d. tests have been considered. Extensions have been carried out to include dependent and multi-state tests. Further on, a scan statistic-based TSCSTFDF procedure (Total Successes Consecutive Successes Total Failures Distant Failures) has been included. We considered also the possibility of assigning weights to the tests and observing the total weight of runs of successes and failures. The single dimensional theory has been generalized to include the possibility of testing in parallel a number of units. This obviously shortens a lot the time of testing.

The alternative Markov Chain Embedding (MCE) approach involves the inversion of large scale matrices. Thus, there exist examples for which we couldn't apply that technique and it was needed to use the present combinatorial approach. In some cases, it has been observed that the results were achieved in much shorter time than using MCE.

All in all, the underlying technique appears to be simple and it is rather efficient and practical for application.

\section{References}

Antzoulakos, A., Koutras, M. V., \& Rakitzis, A. C. (2009). Start-up demonstration tests based on run and scan statistics. Journal of Quality Technology, 41(1), 48-59.

Balakrishnan, N., \& Chan, P. S. (2000). Start-up demonstration tests with rejection of units upon observing $d$ failures. Annals of the Institute of Statistical Mathematics, 52(1), 184-196.

Balakrishnan, N., Koutras, M. V., \& Milienos, F. S. (2014). Start-up demonstration test: Models, Methods and Applications, with some unifications. Applied Stochastic Models in Business and Industry, 30(4), 373-413.

Eryilmaz, S. (2010). Review of recent advances in reliability of consecutive k-out-of-n and related systems. Proceedings of the Institution of Mechanical Engineers, Part O, 224(3), 225-236.

Eryilmaz, S., \& Aksoy, T. (2010). Reliability of linear (n, f, k) systems with weighted components. Journal of Systems Science and Systems Engineering, 19(3), 277-284.

Eryilmaz, S., \& Chakraborti, S. (2008). On start-up demonstration tests under Exchangeability. IEEE Transactions on Reliability, 57(4), 627-632.

Eryilmaz, S., \& Sarikaya, K. (2014). Modeling and analysis of weighted-k-out-f-n:G system consisting of two different types of components. Proceedings of the Institute of Mechanical Engineers, Part $O$, $228(3), 265-271$.

Eryilmaz, S., \& Tutuncu, G. Y. (2009). Reliability evaluation of linear consecutive-weighted-k-out-of-n:F system. Asia-Pacific Journal of Operations Research, 26(6), 805-816.

Gera, A. E. (2004). Combined k-out-of-n:G and consecutive $\mathrm{k}_{\mathrm{c}}$-out-of-n:G systems. IEEE Transactions on Reliability, 53(4), 523-531.

Gera, A. E. (2010). A new start-up demonstration test. IEEE Transactions on Reliability, 59(1), 128-131. 
International Journal of Mathematical, Engineering and Management Sciences

Vol. 3, No. 3, 195-219, 2018

https://dx.doi.org/10.33889/IJMEMS.2018.3.3-015

Gera, A. E. (2011). A general model for start-up demonstration tests. IEEE Transactions on Reliability, $60(1), 295-304$.

Gera, A. E. (2011). Combined m1-consecutive-kc1-out-of-n and m2-consecutive-kc2-out-of-n systems. IEEE Transactions on Reliability, 60(2), 493-497.

Gera, A. E. (2013). A general multi-state start-up demonstration testing procedure. International Journal of Reliability, Quality and Safety Engineering, 20(4), 36-49.

Gera, A. E. (2013). A start-up demonstration procedure involving dependent tests. Statistics and Probability Letters, 83(10), 2191-2196.

Gera, A. E. (2013). A start-up demonstration test involving distant failures. Journal of Quality and Reliability Engineering, Article ID 469546, 1-6.

Gera, A. E. (2014). Discussion paper: start-up demonstration tests, method and application with some unification. Applied Stochastic Models in Business and Industry, 30, DOI: 10.1002/asmb. 2048, 417419.

Gera, A. E. (2015). Different weights of tests within a start-up demonstration procedure. Applied Stochastic Models in Business and Industry, 32(1), 48-56.

Gera, A. E. (2015). Start-up demonstration tests involving a two-dimensional TSCSTFCF procedure. International Journal of Reliability, Quality and Safety Engineering, 22(1).

Hahn, G. J., \& Gage, J. B. (1983). Evaluation of a start-up demonstration test. Journal of Quality Technology, 15(3), 103-106.

Kamalija, K. K., \& Amrutkar, K. P. (2014). Computational methods for reliability and importance measures of weighted-consecutive-systems. IEEE Transactions on Reliability, 63(1), 94-104.

Kuo, W., \& Zuo, M. J. (2003). Optimal reliability modeling, principles and applications, New York, NY: John Wiley \& Sons.

Martin, D. E. K. (2004). Markovian start-up demonstration tests with rejection of units upon observing $d$ failures. European Journal of Operational Research, 155(2), 474-486.

Martin, D. E. K. (2008). Application of auxiliary Markov chains to start-up demonstration tests. European Journal of Operational Research, 184(2), 574-583.

Rakitzis, A. C., \& Antzoulakos, A. (2015). Start-up demonstration tests with three-level classification. Statistical Papers, 56(1), 1-21.

Smith, M. L., \& Griffith, W. S. (2005). Start-up demonstration tests based on consecutive successes and total failures. Journal of Quality Technology, 37(3), 186-198.

Smith, M. L., \& Griffith, W. S. (2008). The analysis and comparison of start-up demonstration tests. European Journal of Operation Research, 186(3), 1029-1045.

Smith, M. L., \& Griffith, W. S. (2011). Multi-state start-up demonstration tests. International Journal of Reliability Quality and Safety Engineering, 18(2), 99-117.

Vellaisamy, P. (1996). On the number of successes in dependent trial communications. Statistics-Theory and Methods, 25(8), 1745-1756.

Vellaisamy, P., \& Upadhye, N. S. (2007). On the negative binomial distribution and its generalizations. Statistics and Probability Letters, 77(2), 173-180.

Viveros, R., \& Balakrishnan, N. (1993). Statistical inference from start-up demonstration test data. Journal of Quality Technology, 25(2), 119-130. 
International Journal of Mathematical, Engineering and Management Sciences

Vol. 3, No. 3, 195-219, 2018

https://dx.doi.org/10.33889/IJMEMS.2018.3.3-015

Yalcin, F., \& Eryilmaz, S. (2012). Start-up demonstration test based on total successes and total failures with dependent start-ups. IEEE Transactions on Reliability, 61(1), 227-230.

Zhao, X., Cui, L. R., \& Xie, W. J. (2010). On parallel start-up demonstration test. Proceedings of the 4-th Asia-Pacific International Symposium on Advanced Reliability and Maintainability, 851-857.

Zhao, X., Sun, G., Xie, W., \& Lin, C. (2015). On generalized multi-state start-up demonstration tests. European Journal of Operational Research, 31(3), 325-338.

Zhao, X.,Wang, X., \& Sun, G. (2015). Start-up demonstration tests with sparse connection. European Journal of Operation Research, 243(3), 865-873.

Zuo, M. J. (1993). Reliability and design of 2-dimensional consecutive- $k$-out-of- $n$ systems. IEEE Transactions on Reliability, 42(3), 488-490. 